\title{
Fermilab-FN-0966-APC
}

August 2013

\section{MARS15 SIMULATION FOR THE MESON CENTER TEST BEAMS}

\author{
N.V. Mokhov and Y.I. Eidelman \\ Fermilab, Batavia, IL 60510, U.S.A.
}

\begin{abstract}
The MARS15 code is used to calculate prompt dose and star densities in areas of interest at the Meson Center Test Beam. The beamline components and adjoining infrastructure are implemented in great detail into the model. Simulations are carried out for $120-\mathrm{GeV} / \mathrm{c}$ protons on target and the beamline tuned to 5 $\mathrm{GeV} / \mathrm{c}, 16 \mathrm{GeV} / \mathrm{c}$, and $85 \mathrm{GeV} / \mathrm{c}$. It is found that prompt dose rates and radiation loads to the sump water are within tolerable levels.
\end{abstract}

\section{The Model}

The Meson Center (MCenter) Test Beam and adjoining infrastructure are implemented in great detail into the MARS15 [1] model of the MCenter. Magnets are placed as per the beamsheet; the fields are set as per the settings used in MIPP (E-907 experiment). The shielding in MC6 is based on Radiation Safety drawings. Adjoining infrastructure in based on FESS drawings. The model has also been verified in the field. Fig. 1 shows an elevation section of the MARS model through the beamline while Fig. 2 shows a plan section at primary beam height. The areas of interest are shown in the figures with their description given in Table 1.

The magnets were set as per the MIPP experiment. As fields and gradients scaled linearly with momentum, this was straight forward. Three momenta were chosen: $5 \mathrm{GeV} / \mathrm{c}, 16 \mathrm{Gev} / \mathrm{c}$, and $85 \mathrm{GeV} / \mathrm{c}$. The lowest momentum realistically achievable, due to power supply stability, is $5 \mathrm{GeV} / \mathrm{c}$. The maximum allowable momentum is $85 \mathrm{GeV} / \mathrm{c}$. The expected startup momentum is $16 \mathrm{GeV} / \mathrm{c}$. The MARS built-in material parameters were used in this study. These included copper (target), iron, concrete, heavy concrete, soil, and air. All results are normalized to $120 \mathrm{GeV} / \mathrm{c}$ protons on target at the rate of $6.01 \mathrm{E} 12$ protons per hour, which is commensurate with the anticipated 1 E11 protons per (four second) spill every minute. This corresponds to the average $1.67 \mathrm{Eg}$ protons per second on target. In some runs particles were tracked in MARS15 to the threshold energy of $0.001 \mathrm{eV}$ (neutrons) and $100 \mathrm{keV}$ (all other particles); in others the overall threshold energy was $20 \mathrm{MeV}$. 


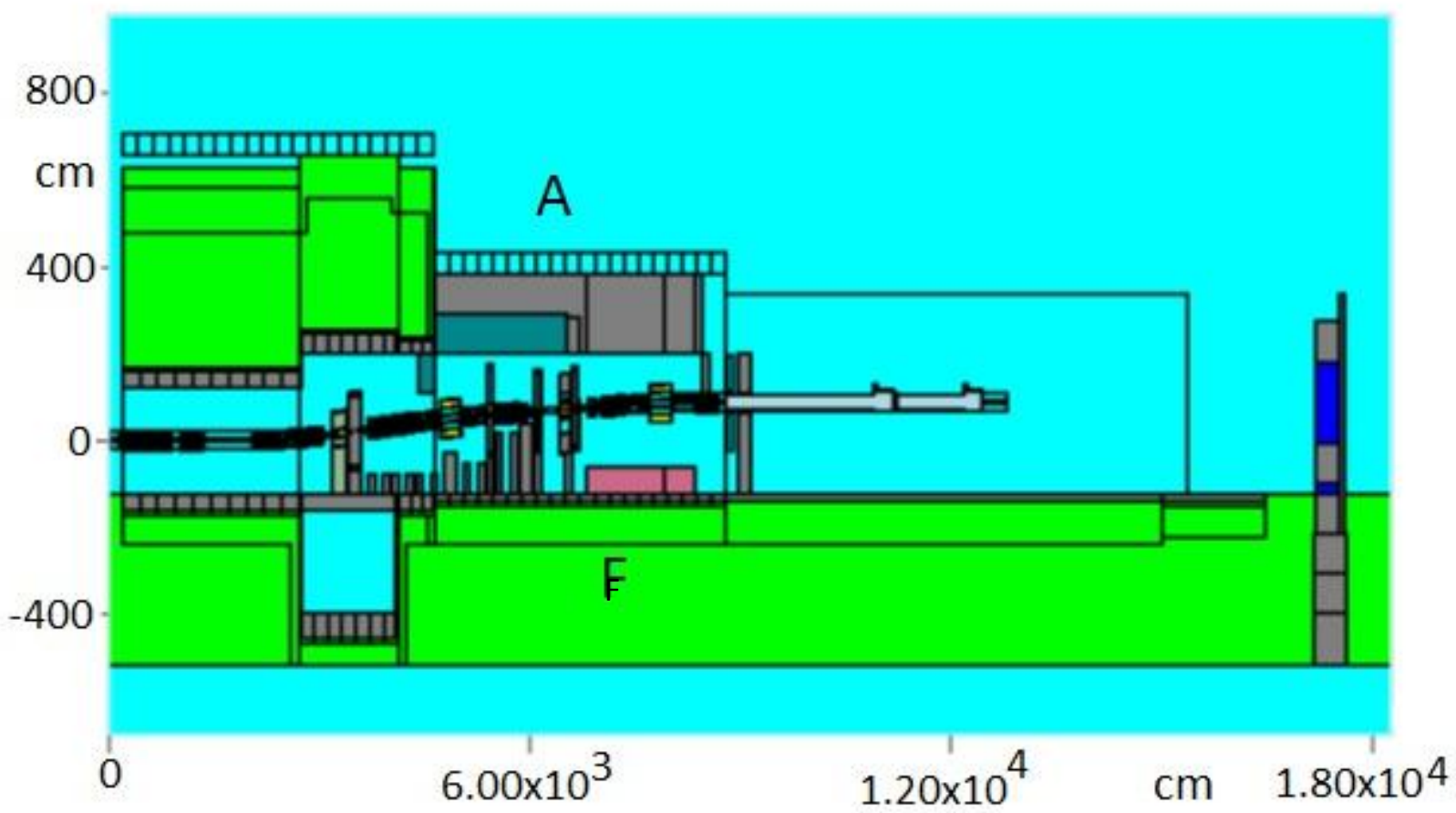

Figure 1. Elevation section of the MCenter MARS model with areas of interest labeled.

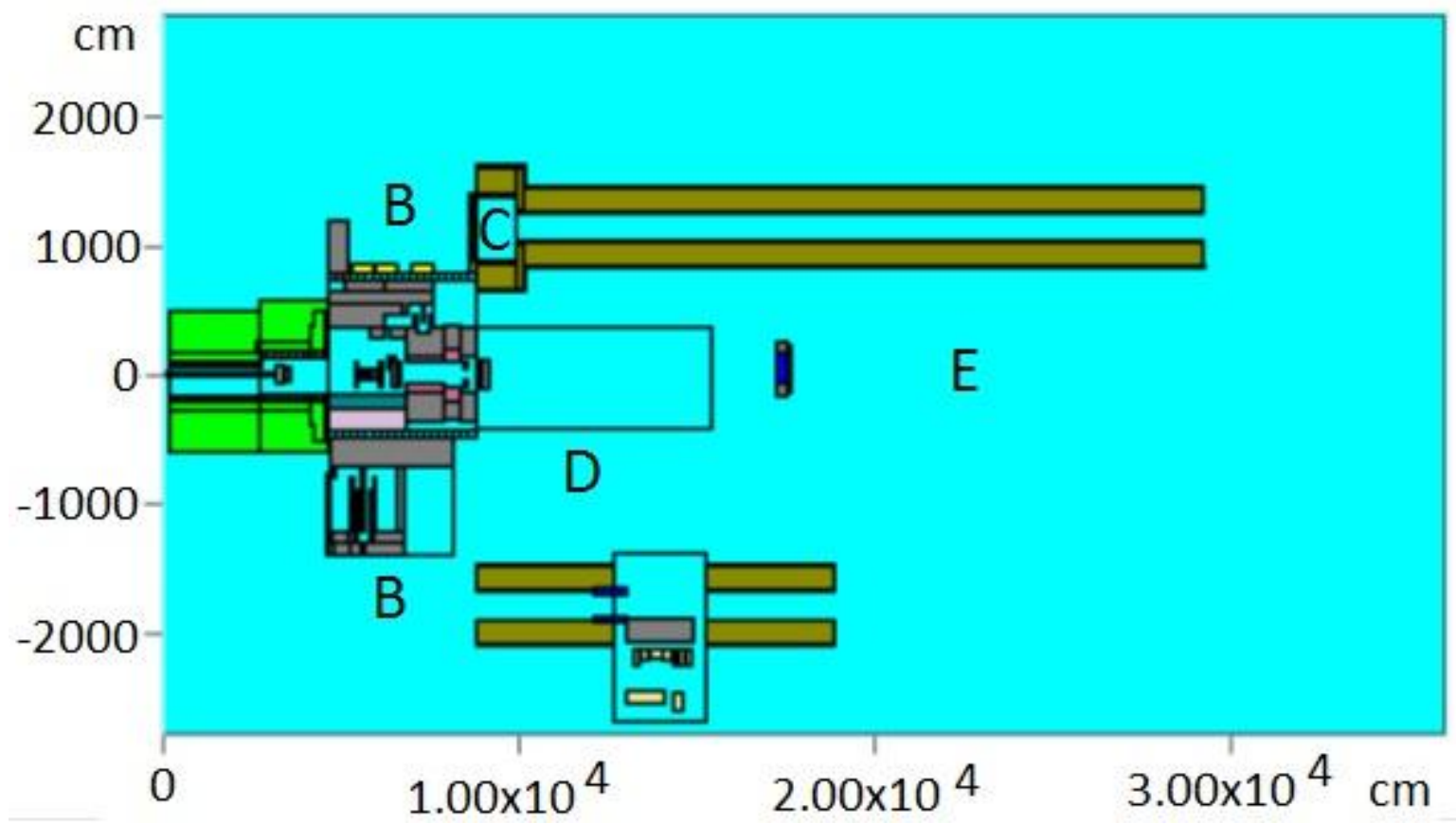

Figure 2. Plan section of the MCenter MARS model with areas of interest labeled. 
Table 1: Areas of interest with regard to prompt dose or star density.

\begin{tabular}{|l|c|c|c|}
\hline Area & Quantity & Label & Figure \\
\hline $\begin{array}{l}\text { Top of the target } \\
\text { pile }\end{array}$ & dose & A & 1 \\
\hline $\begin{array}{l}\text { Floor of the } \\
\text { Meson detector } \\
\text { building }\end{array}$ & dose & B & 2 \\
\hline New control room & dose & C & 2 \\
\hline $\begin{array}{l}\text { Outside areas } \\
\text { within the } \\
\text { radiation fence }\end{array}$ & dose & D & 2 \\
\hline $\begin{array}{l}\text { Area beyond the } \\
\text { radiation fence }\end{array}$ & dose & E & 1 \\
\hline $\begin{array}{l}\text { Below the floor of } \\
\text { the Meson } \\
\text { detector building }\end{array}$ & stars & & \\
\hline
\end{tabular}

\section{Model Extensions and Tests}

The origin of the MCenter MARS model for this study was the one created in Reference [2]. It was substantially extended and verified with the drawings and in the field. The elements added in the new MARS model are listed in Table 2 and shown in Figs. 3 and 4 . Note that a muon absorber downstream of MC7 (see Section 5 on $85-\mathrm{GeV} / \mathrm{c}$ mode) was added at the very end of these studies and is not shown in Figs. 3 and 4.

Table 2: New elements added in the 2013 MCenter MARS15 model.

\begin{tabular}{|c|l|}
\hline No. & New elements \\
\hline 1 & Concrete floor under the proton target (MC6 building) \\
\hline 2 & Concrete stands under elements (MC6) \\
\hline 3 & Additional concrete blocks as a part of the shielding system (MC6) \\
\hline 4 & Eight Tevatron magnets stored as a part of the shielding system (MC6) \\
\hline 5 & Old control room \\
\hline 6 & Steel frames of the MC5 and MC7 buildings \\
\hline 7 & MW and MP beam enclosures \\
\hline 8 & Power supplies and electronics inside MC5 building with their shielding \\
\hline 9 & New control room \\
\hline 10 & Soil and air regions wherever needed \\
\hline 11 & Muon absorber downstream MC7 \\
\hline
\end{tabular}




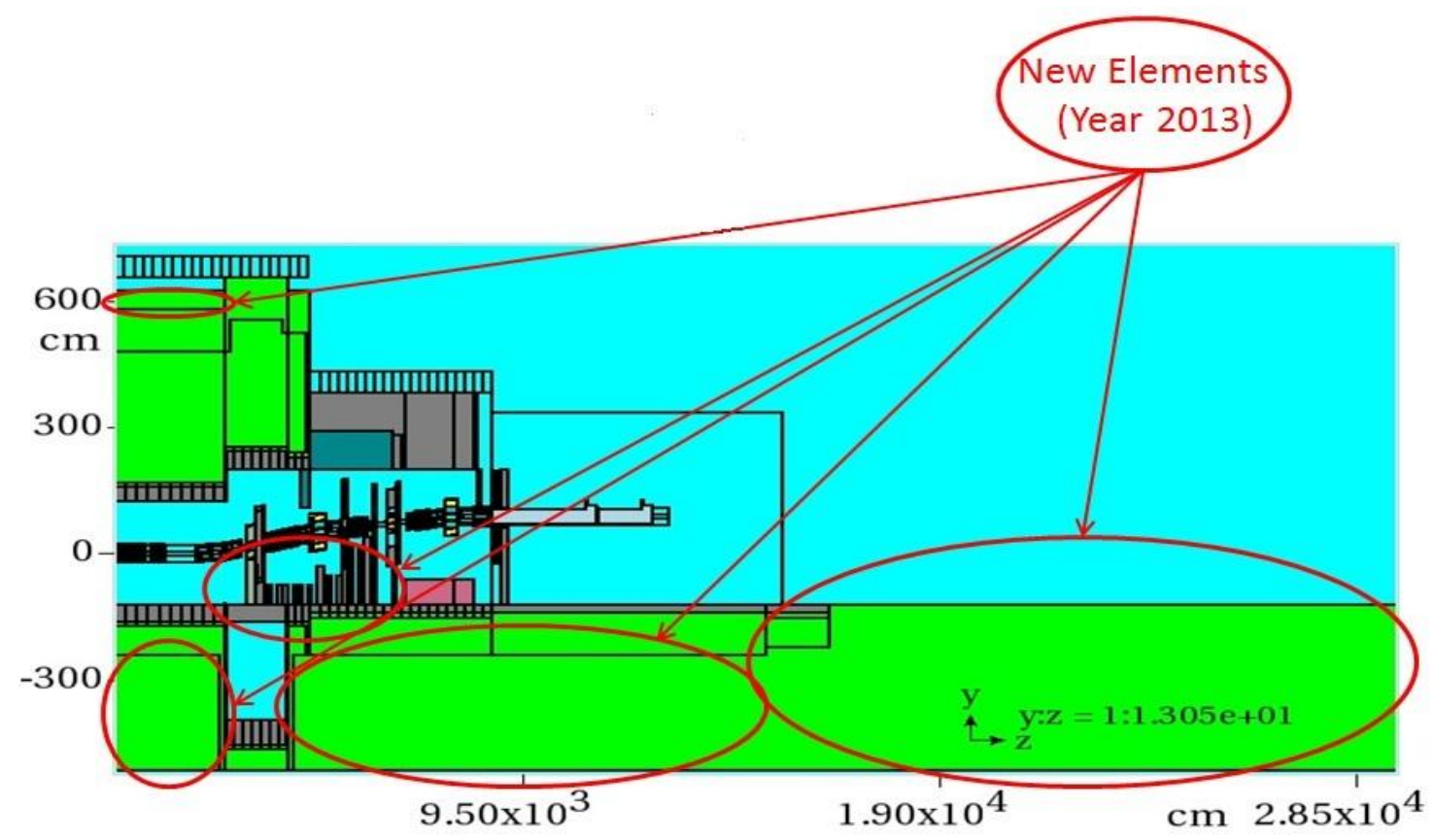

Figure 3. Elevation view showing new elements of the MCenter MARS model.

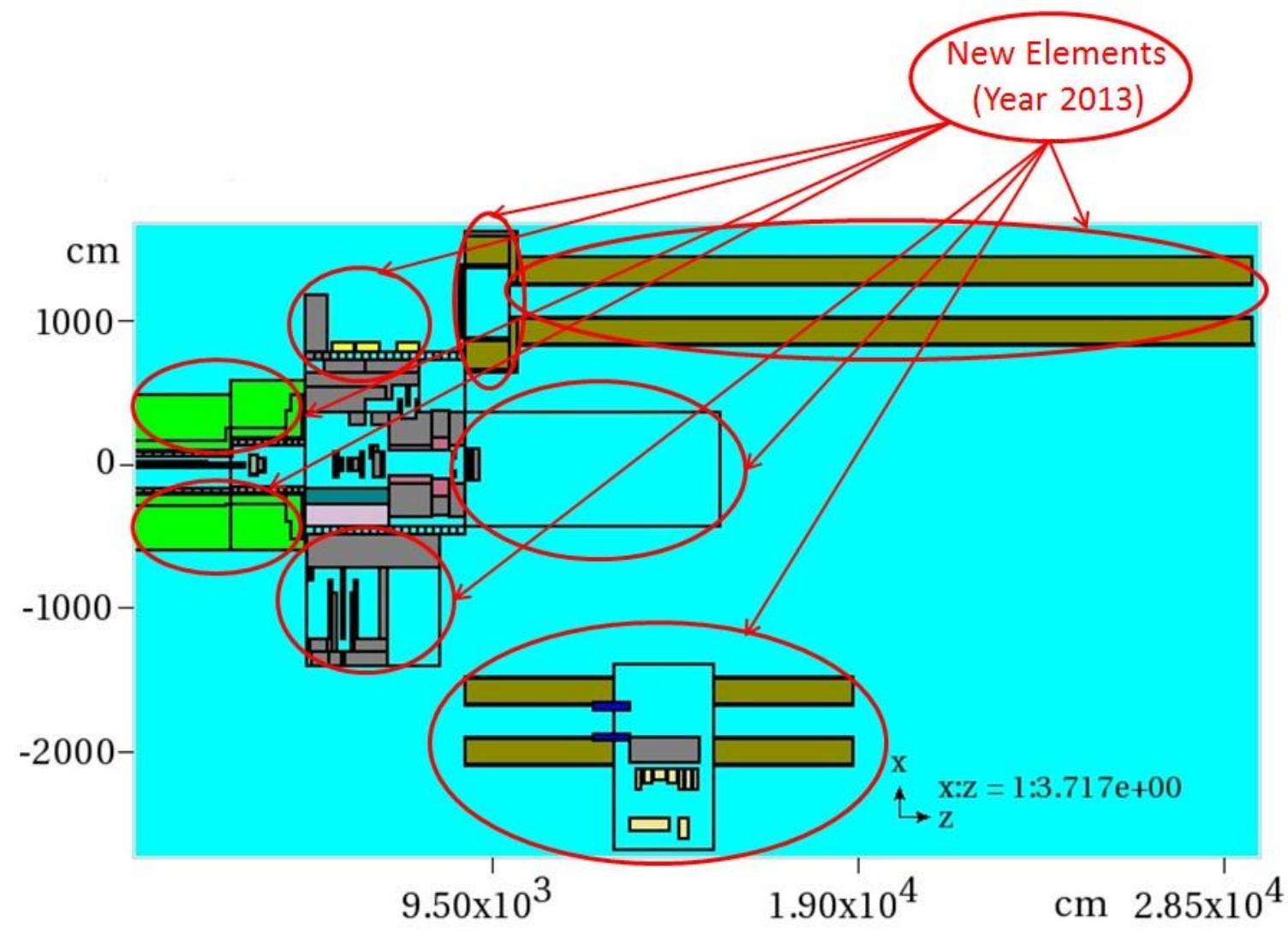

Figure 4. Plan view showing new elements of the MCenter MARS model. 
Fig. 5 shows the key components of the MCenter beamline as implemented in the MARS model. The performance of the built beamline model was carefully tested at all the three beam momenta with vacuum in the aperture. Fig. 6 shows results of a tracking test for $5-\mathrm{GeV} / \mathrm{c}$ protons. The same performance is found for two other beam momenta.

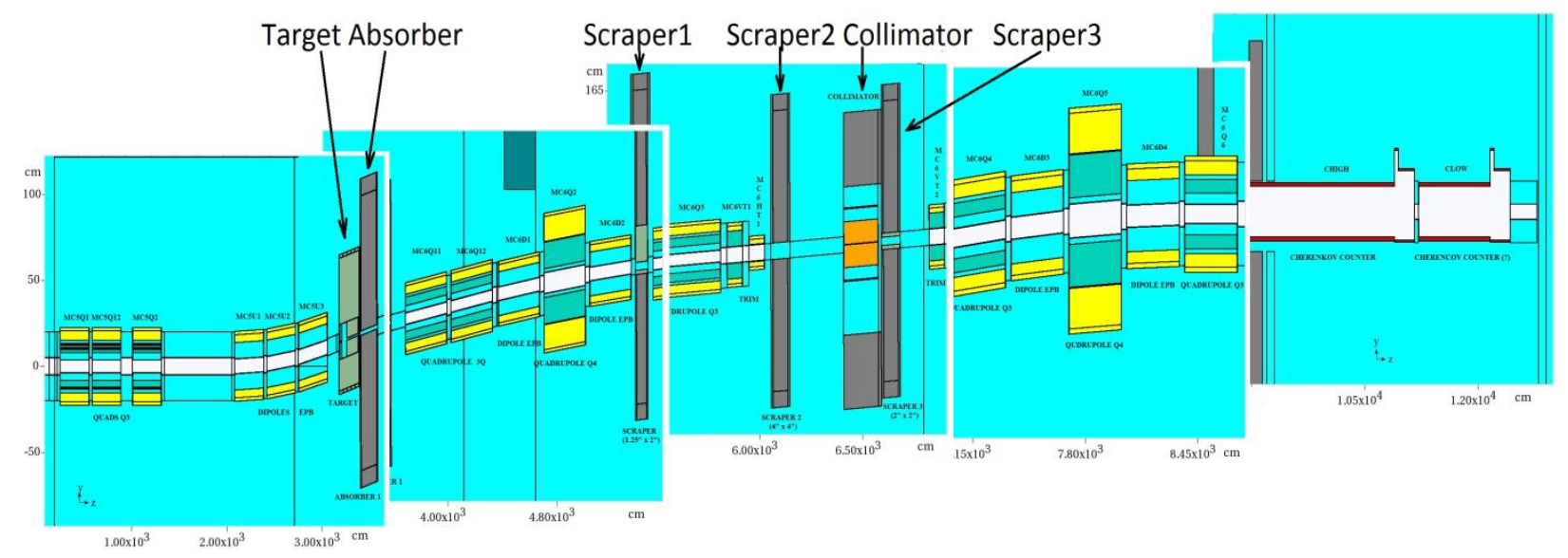

Figure 5. MCenter beamline MARS15 model.

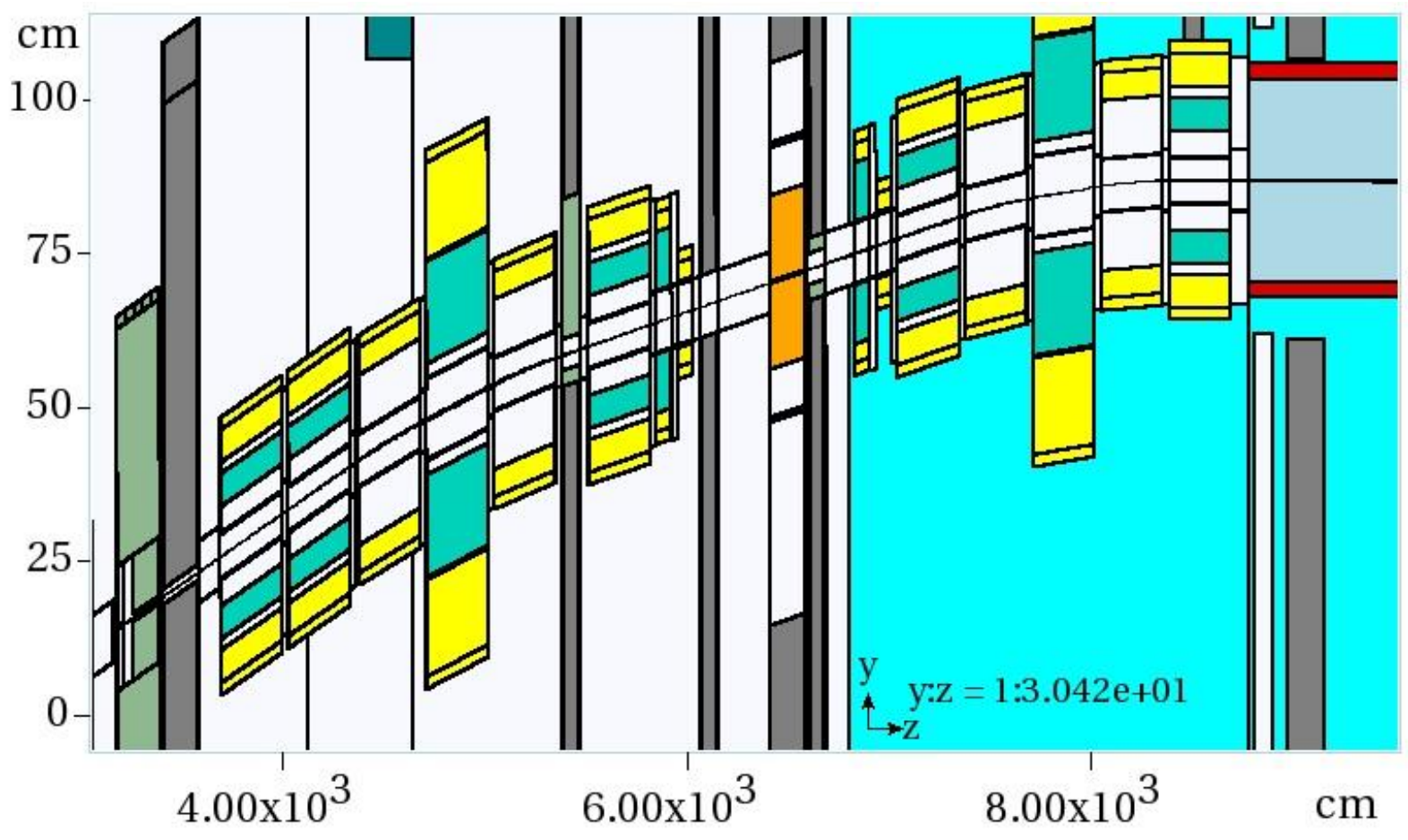

Figure 6. Tracking test for $5-\mathrm{GeV} / \mathrm{c}$ protons. 
In reality, there is air in the MCenter beamline aperture. It makes a big difference compared to the vacuum case for a $5-\mathrm{GeV} / \mathrm{c}$ beam (Fig. 7), slightly affects the proton beam tracking at $85 \mathrm{GeV} / \mathrm{c}$ (Fig. 8 ), and substantially affects the secondary particle tracking in the beamline for all the three beam momenta.

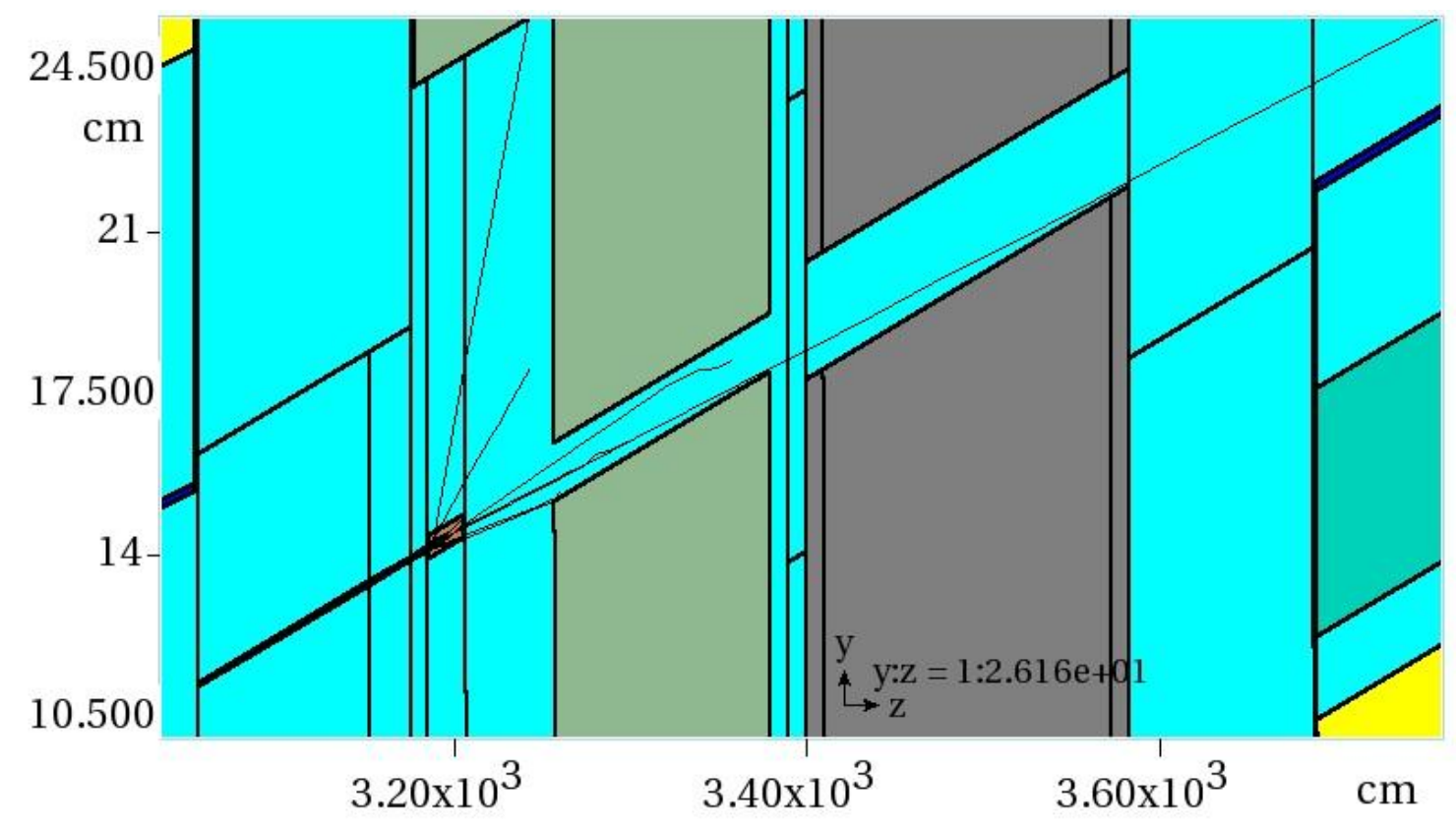

Figure 7. Tracking test for $5-\mathrm{GeV} / \mathrm{c}$ proton beam on target with air in aperture.

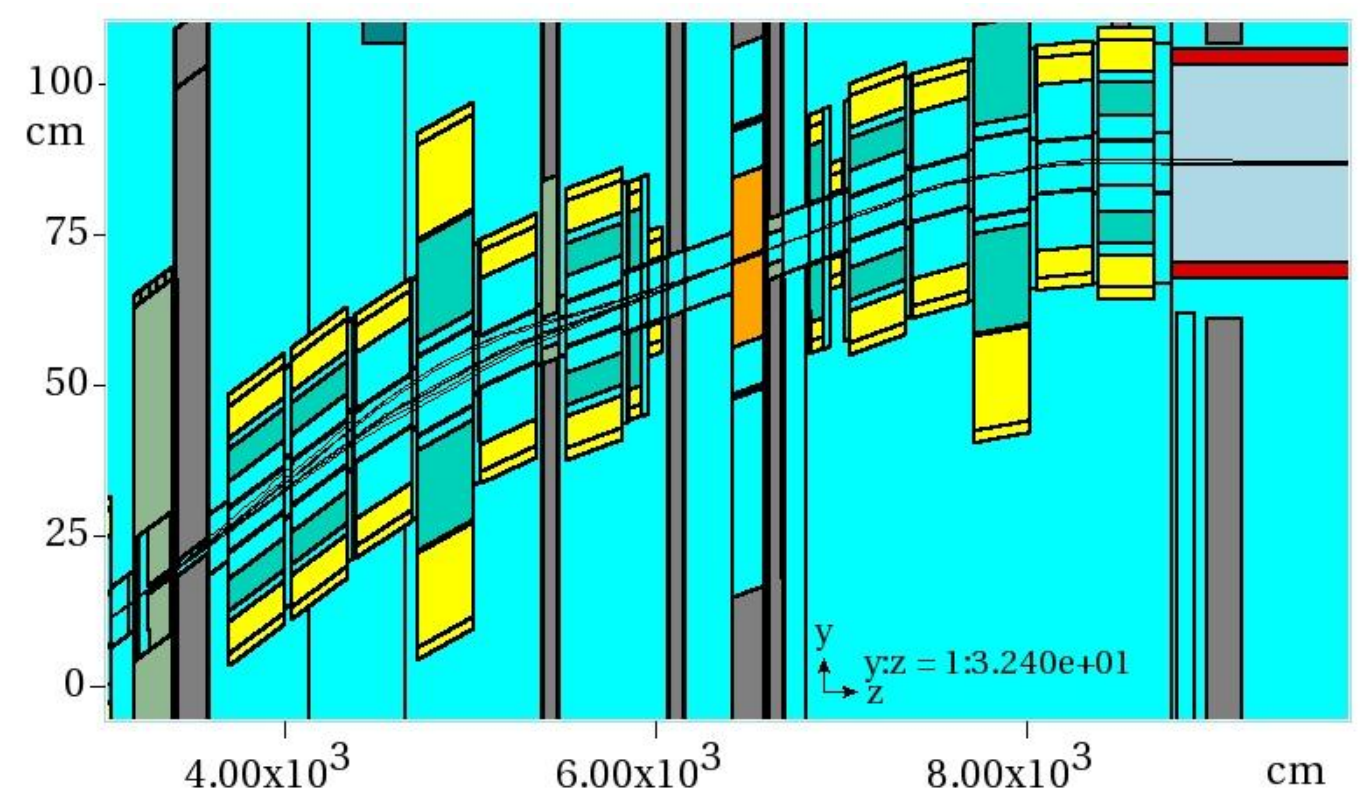

Figure 8. Tracking test for $85-\mathrm{GeV} / \mathrm{c}$ proton beam on target with air in aperture. 


\section{Results for $5 \mathrm{GeV} / \mathrm{c}$ Beam}

At the beginning of this study, calculations for the $5-\mathrm{GeV} / \mathrm{c}$ beam case were done with an early version of the 2013 MARS model of the MCenter, without elements No. 1-4, 9 and 11 listed in Table 2. At the end, the calculations were redone for the final model described in Sect 5 . Results of this section are for the final model, with the threshold energy of $20 \mathrm{MeV}$. The effect of threshold energies is discussed in the next section. Prompt dose isocontours (total and muon) in elevation section through the beam line axis are presented in Fig. 9, while Fig. 10 is a magnified view for the total prompt dose and hadron flux ( $\mathrm{E}>30 \mathrm{MeV}$ ). Medium-energy hadrons and low-energy neutrons define the dose in the buildings and immediately outside while dose downstream of the buildings in a near-forward direction is driven by muons, even for such a low beam momentum as $5 \mathrm{GeV} / \mathrm{c}$.
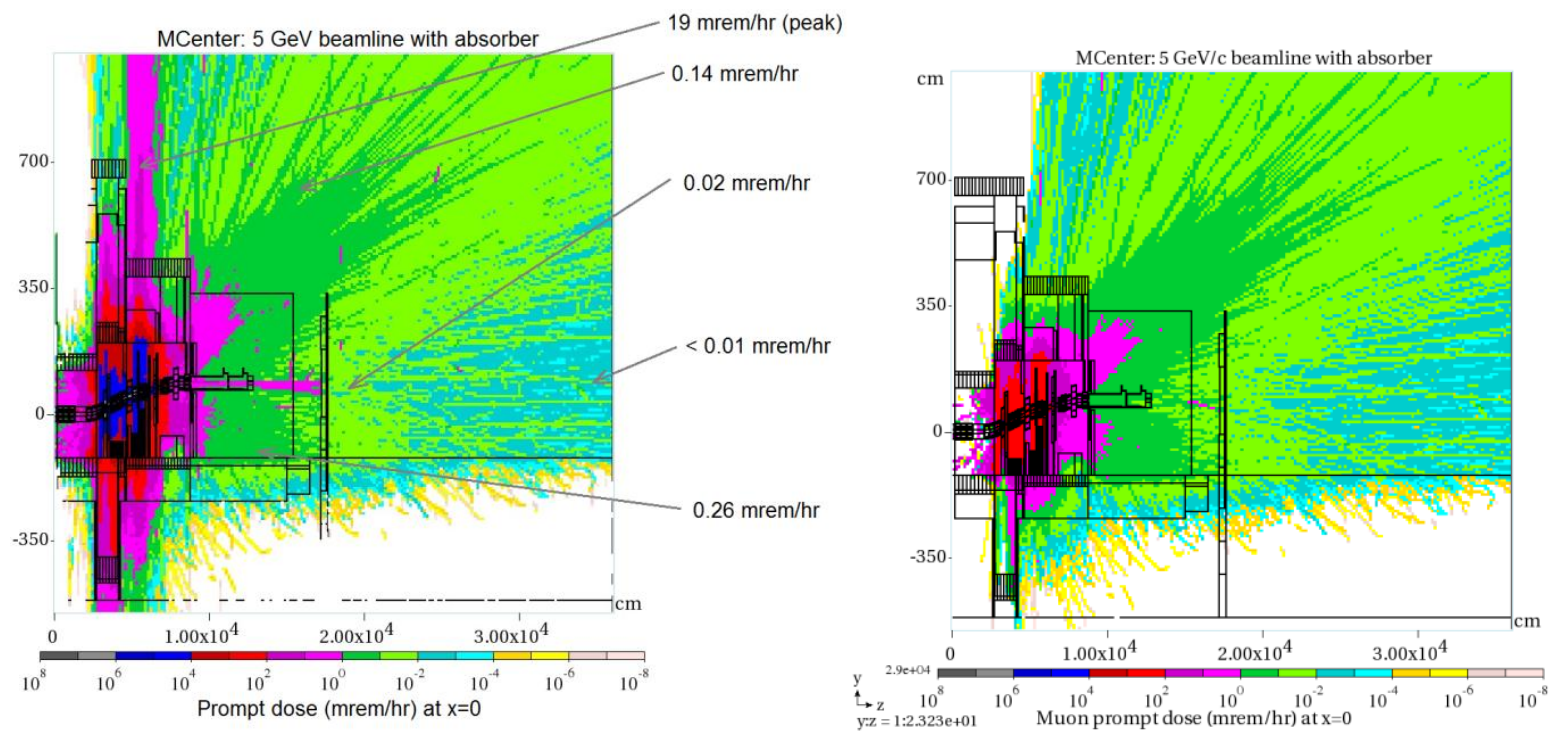

Figure 9. Total (left) and muon (right) prompt dose - elevation section.
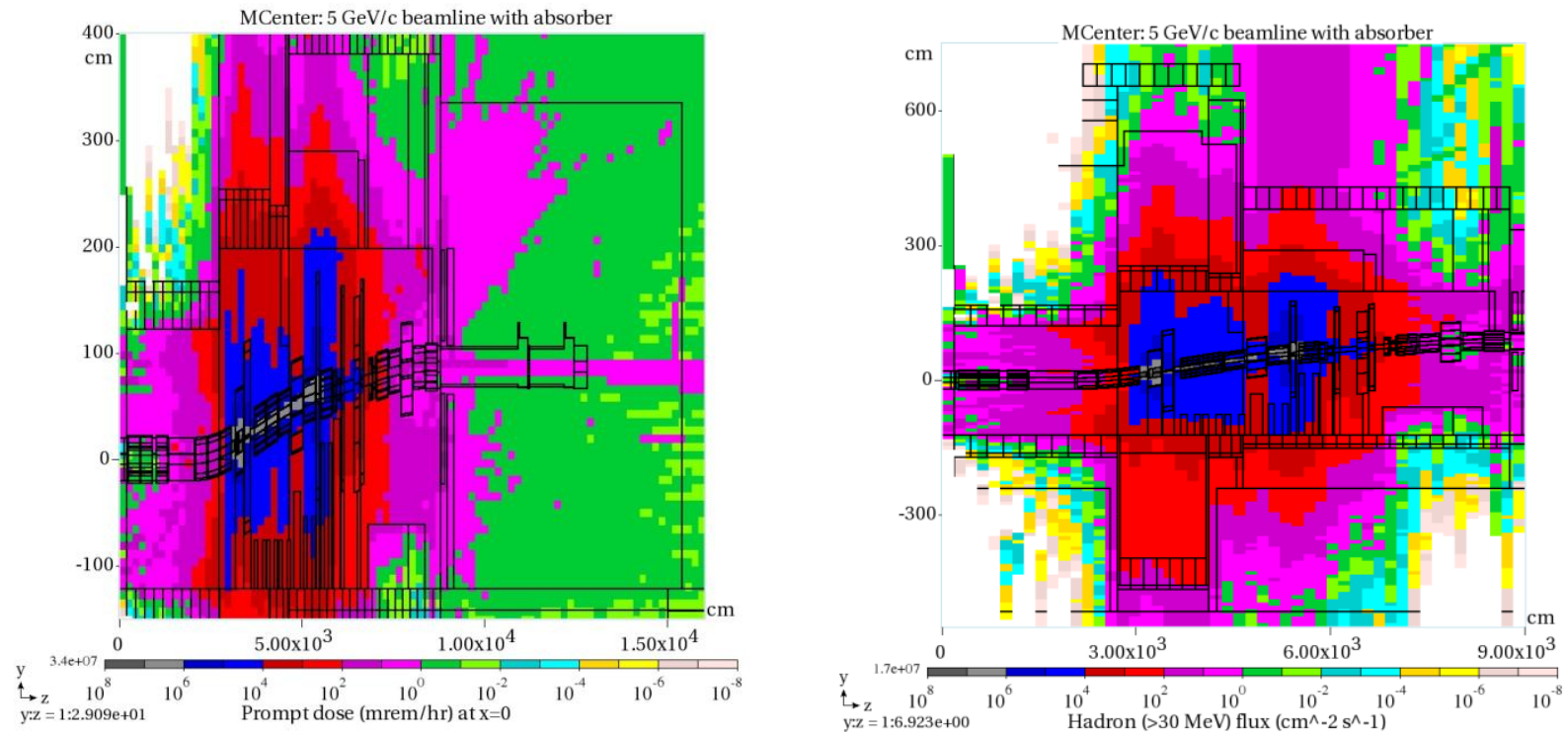

Figure 10. Total prompt dose (left) and hadron flux (right) in the MC6 region - elevation section. 
Fig. 11 shows distributions of prompt dose in plan sections at the beamline height prior to the target $(\mathrm{y}=0)$ and downstream of MC6 $(\mathrm{y}=90 \mathrm{~cm})$.
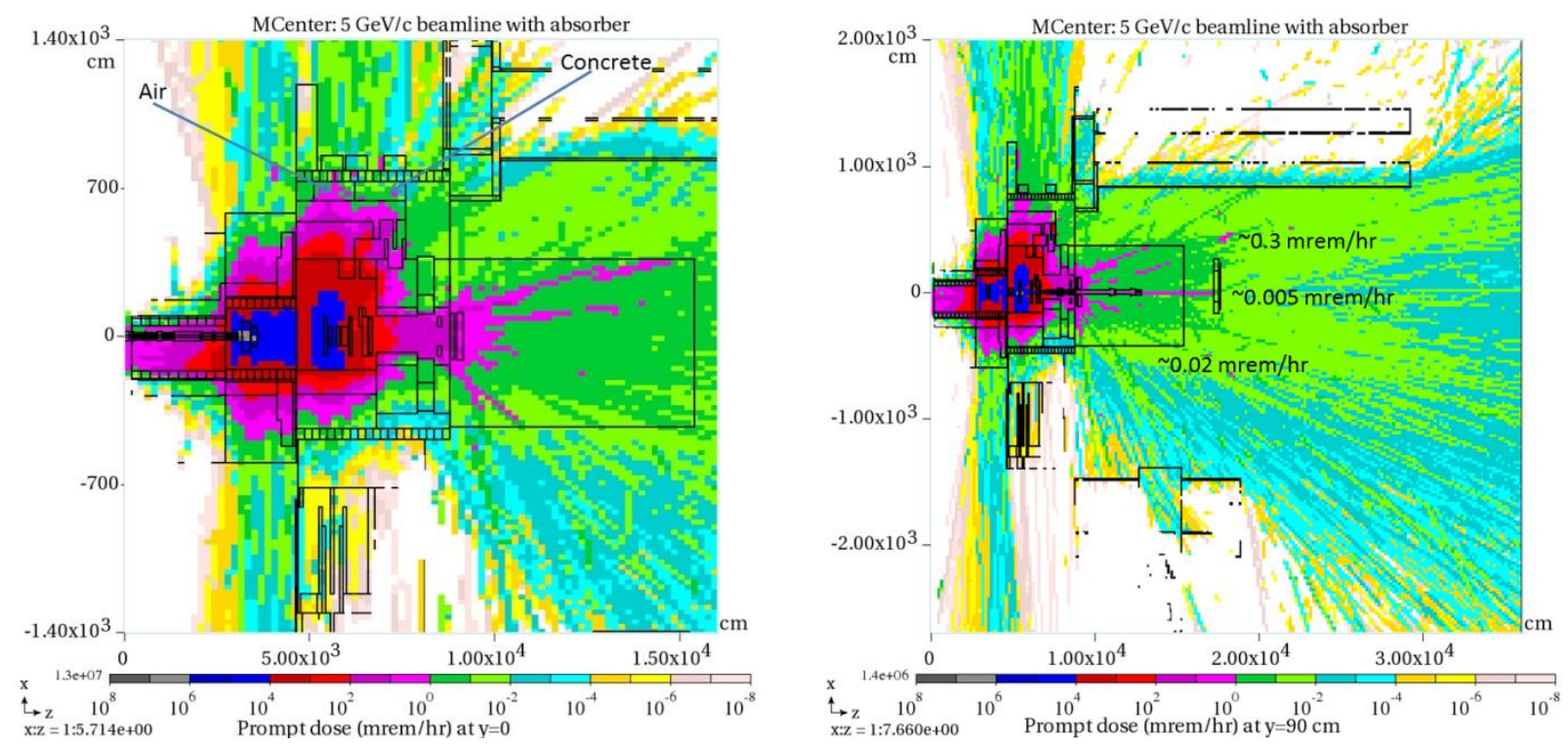

Figure 11. Prompt dose in central region at elevation $y=0$ (left) and $y=90 \mathrm{~cm}$ (right) - plan section.

\section{Results for $16 \mathrm{GeV} / \mathrm{c}$ Beam}

This section describes results of MARS15 simulations for the expected startup momentum of 16 $\mathrm{GeV} / \mathrm{c}$. Calculations were done for the extended MCenter model (but without muon absorber included in the model later) as described at the end of the previous section. Details of the model in MC6 are shown in Fig. 12. For this model and $16-\mathrm{GeV} / \mathrm{c}$ beamline, we have run MARS in two different modes:

1. The lowest threshold energies of $0.001 \mathrm{eV}$ for neutrons and $100 \mathrm{keV}$ for all other particles; this is quite CPU-time consuming even without variance reduction techniques for thick shielding applications. This mode is optimal and gives correct results on prompt dose inside the MC buildings, but underestimates the radiation quantities outside.

2. The threshold energy of $20 \mathrm{MeV}$ for all particles heavily using the variance reduction techniques. This mode somewhat underestimates the prompt dose inside the buildings but gives reliable results on the prompt dose outside, behind the thick shielding as well as on the radiation loads on the sump water (star density and hadron flux above $30 \mathrm{MeV}$ ). 

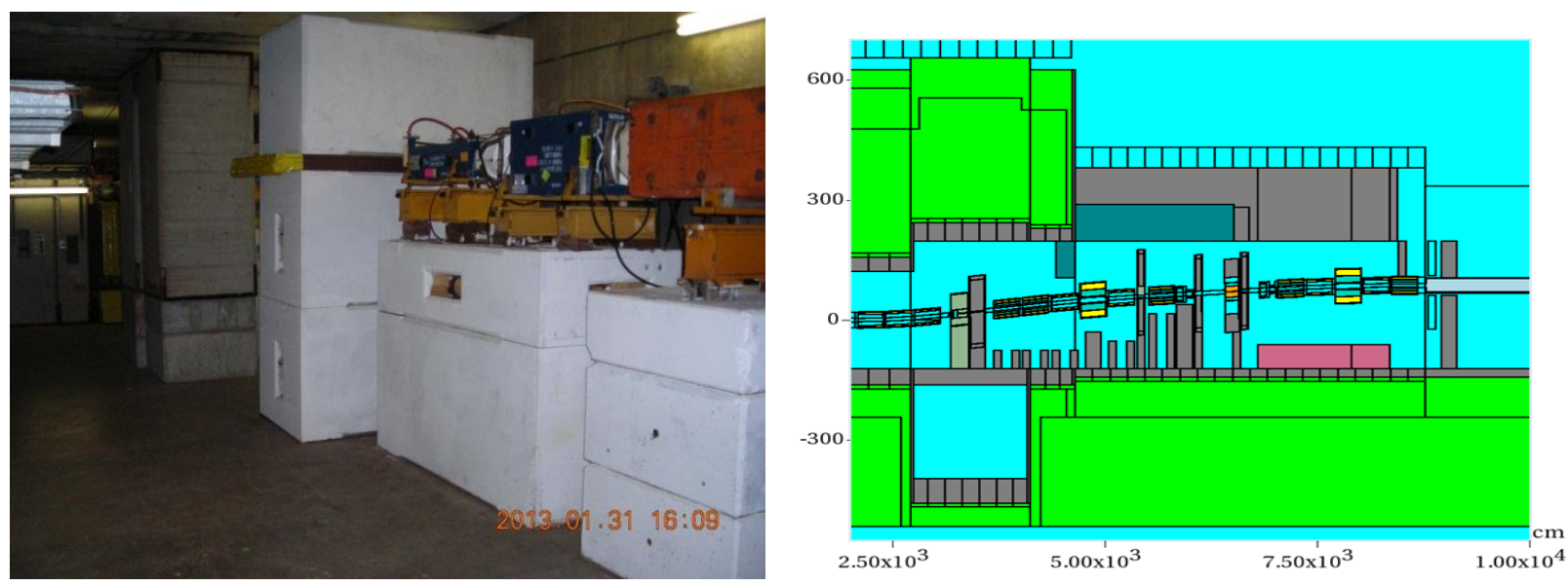

Figure 12. Concrete stands under the beamline components in MC6 (left) and their implementation in the MARS model (right).

Fig. 13 and 14 show prompt dose distributions in the MC6 region calculated in both the modes for the elevation and plan sections, respectively. Pros and cons of each mode are clearly seen by comparing the left and right pictures. Note that in this particular case, the total run times were about the same to get results in both the modes. Mode 2 is more appropriate for this study; therefore most results in this report have been obtained in this mode. In a few instances, mode 1 was used. In one case results of both the modes were combined (see Fig. 16 below).
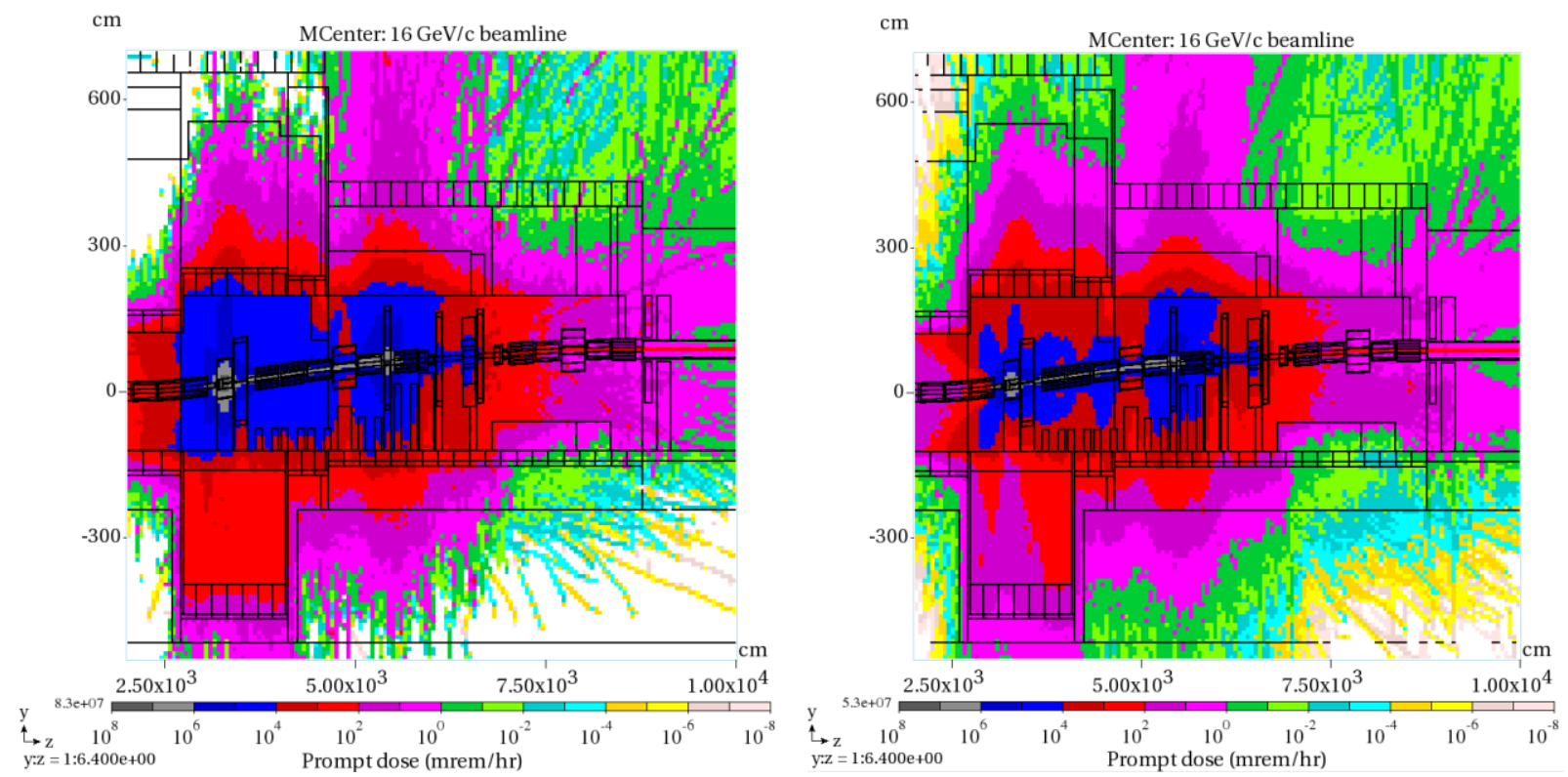

Figure 13. Prompt dose in the MC6 central region for $16-\mathrm{GeV} / \mathrm{c}$ beamline, elevation section: mode 1 (left) and mode 2 (right). 

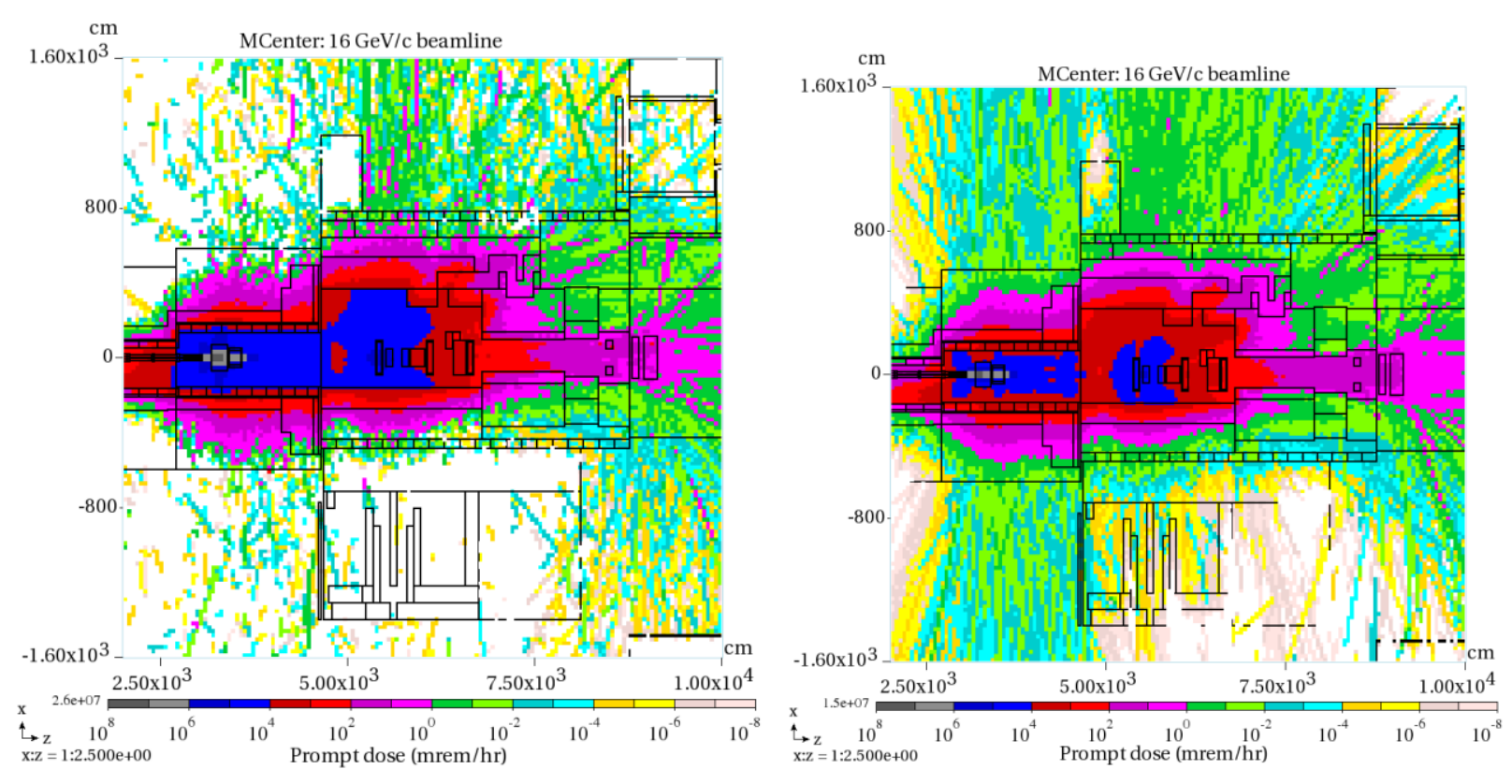

Figure 14. Prompt dose in the MC6 central region for $16-\mathrm{GeV} / \mathrm{c}$ beamline, plan section: mode 1 (left) and mode 2 (right).

Total and muon prompt dose distributions are presented in Figs. 15 and 16 for the elevation and plan sections. The muon component of the dose at the beamline height immediately downstream of MC6 $(y=90 \mathrm{~cm})$ is more pronounced at this momentum compared to the $5-\mathrm{GeV} / \mathrm{c}$ case. The peak dose values in the regions of interest, also shown in the plots, are quite low. Dose in the old and new control rooms is below $0.01 \mathrm{mrem} / \mathrm{hr}$. Eight Tevatron dipole magnets stacked west of MC6 and implemented into the model (see Fig. 17) help reduce the dose over the entire height outside of the west wall to 0.1-1 $\mathrm{mrem} / \mathrm{hr}$.

Fig. 18 shows star density ( $\mathrm{E}>30 \mathrm{MeV}$ ) distribution in MC6 - the hottest region of MCenter. Its value immediately outside the concrete floor characterizes the radiation load to the sump water. The calculated peak in the first $10-\mathrm{cm}$ of soil under the floor is $118 \mathrm{~cm}^{-3} \mathrm{~s}^{-1}$. At the same location, the corresponding peak hadron flux $(\mathrm{E}>30 \mathrm{MeV})$ is $4400 \mathrm{~cm}^{-2} \mathrm{~s}^{-1}$. 


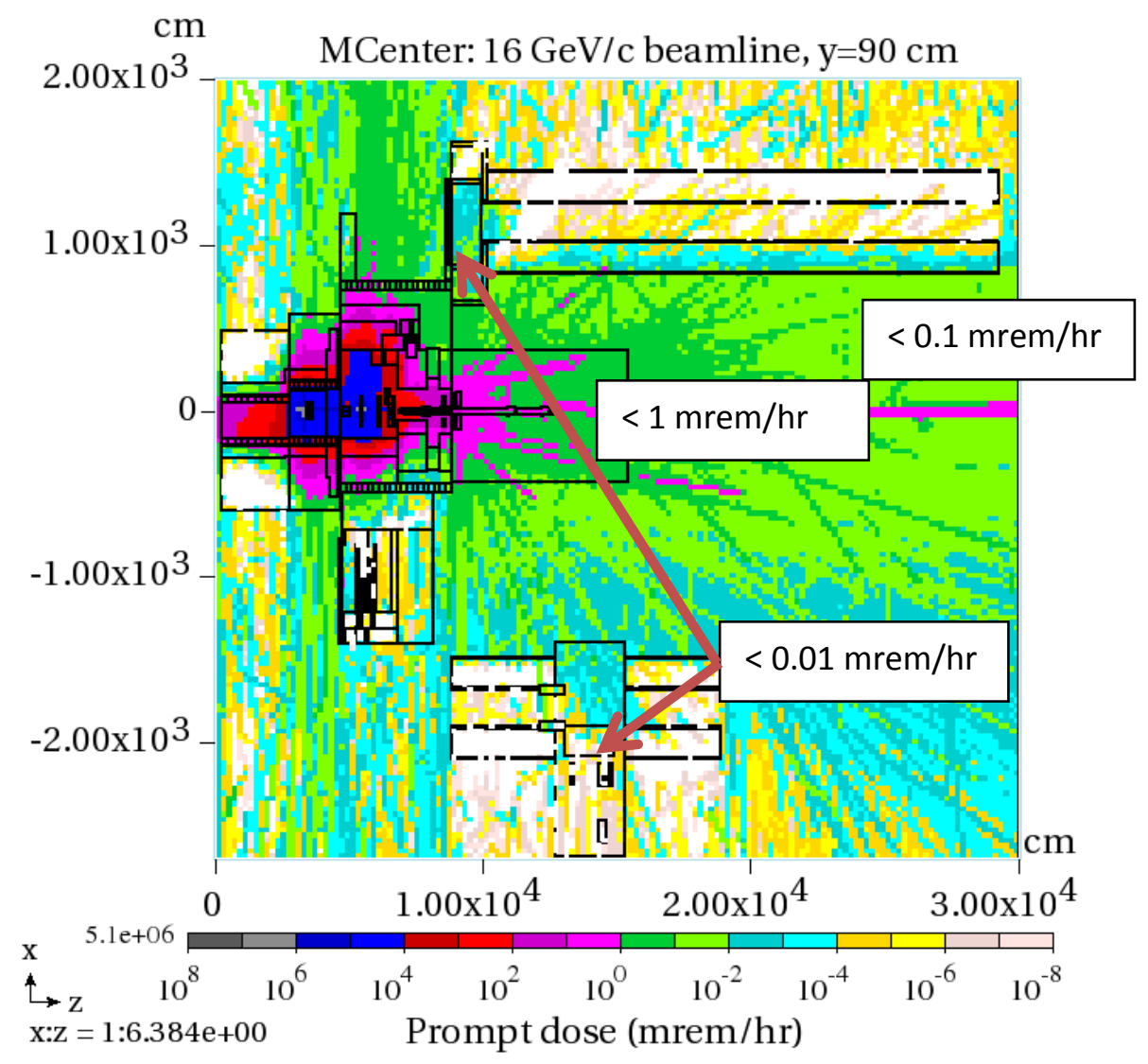

Figure 15. Prompt dose for a $16-\mathrm{GeV} / \mathrm{c}$ beam in the entire region - plan section at $\mathrm{y}=90 \mathrm{~cm}$. The muon absorber is not included in this instance.
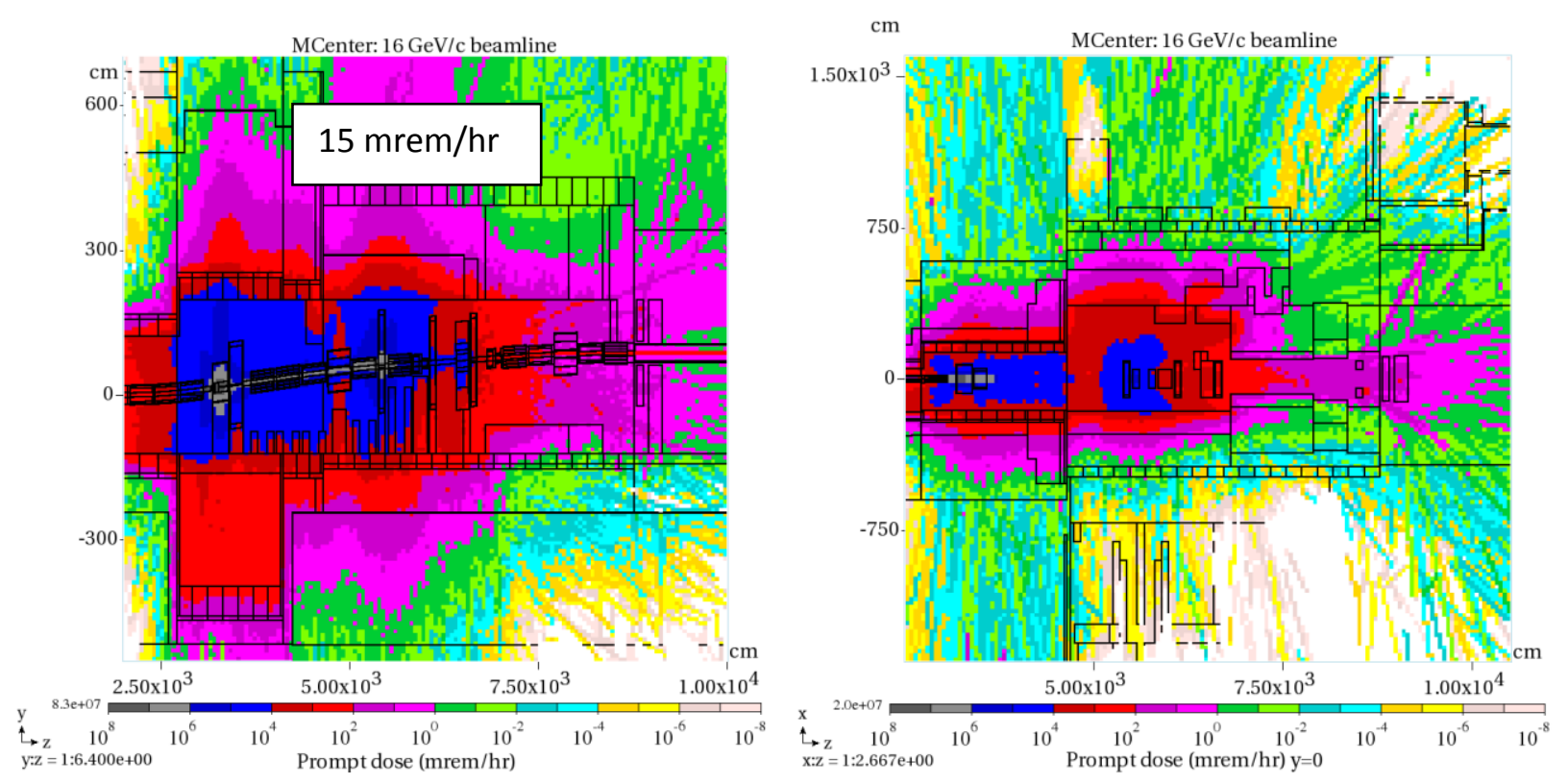

Figure 16. Prompt dose in the central region for a $16-\mathrm{GeV} / \mathrm{c}$ beam: elevation (left) and plan (right) sections. Results of mode 1 and 2 runs are combined here. 


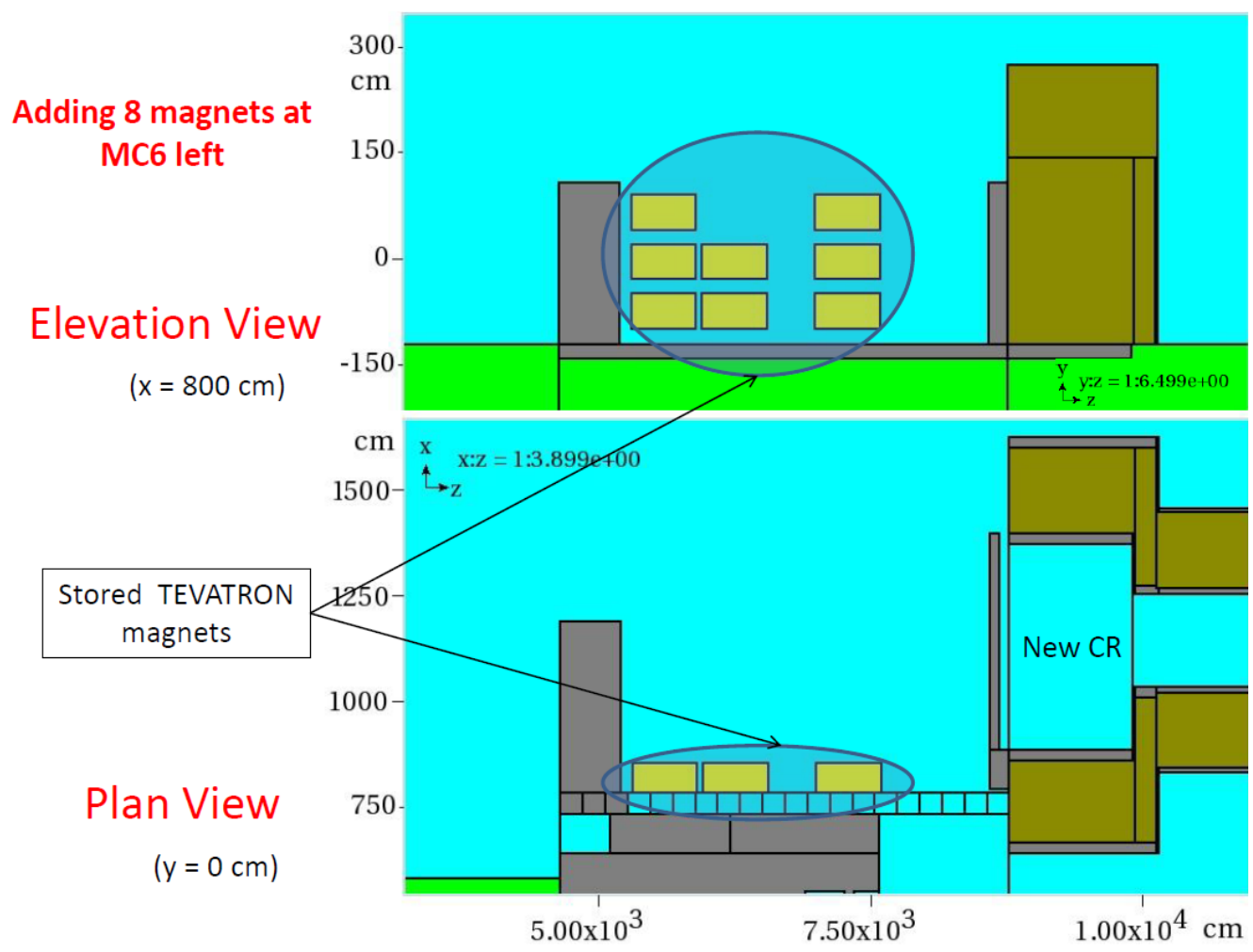

Figure 17. Eight Tevatron dipole magnets to the west of MC6 as implemented in MARS model.

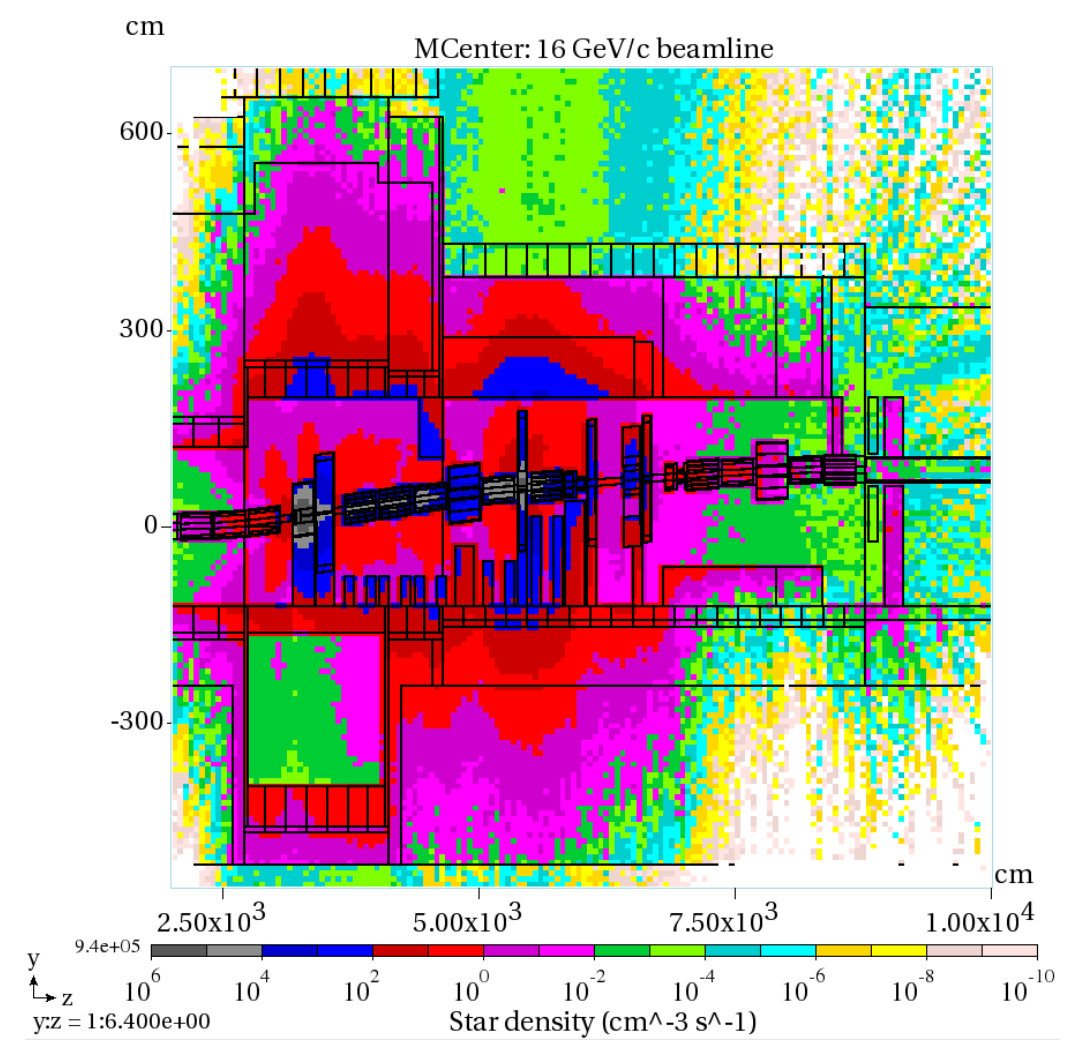

Figure 18. Star density (>30 MeV) distribution in the central region - elevation section. 


\section{Results for $85 \mathrm{GeV} / \mathrm{c}$ Beam}

As proton beam momentum increases, forward-directed muons downstream of MCenter become more dominant. Muon spectra immediately downstream of the MC7 building are presented in Fig. 19. With their mean energy of 3 to $4 \mathrm{GeV}$ and high-energy tail spanning up to the proton beam energy, these muons create a dose along the direction of the beamline in MC7, peaking at 1000 $\mathrm{mrem} / \mathrm{hr}$. This is orders of magnitude above the limits in the region shown in Fig. 20. The steel/concrete absorber installed behind MC7 at $\mathrm{z} \sim 172 \mathrm{~m}$ and implemented into the new MARS15 model (Fig. 21) absorbs most of the low- and medium-energy muons and drastically reduces the energy of the remaining ones. Fig. 22 shows the prompt dose distribution with the finalized model. One sees that even for the highest-momentum mode, the dose is within the limits everywhere.

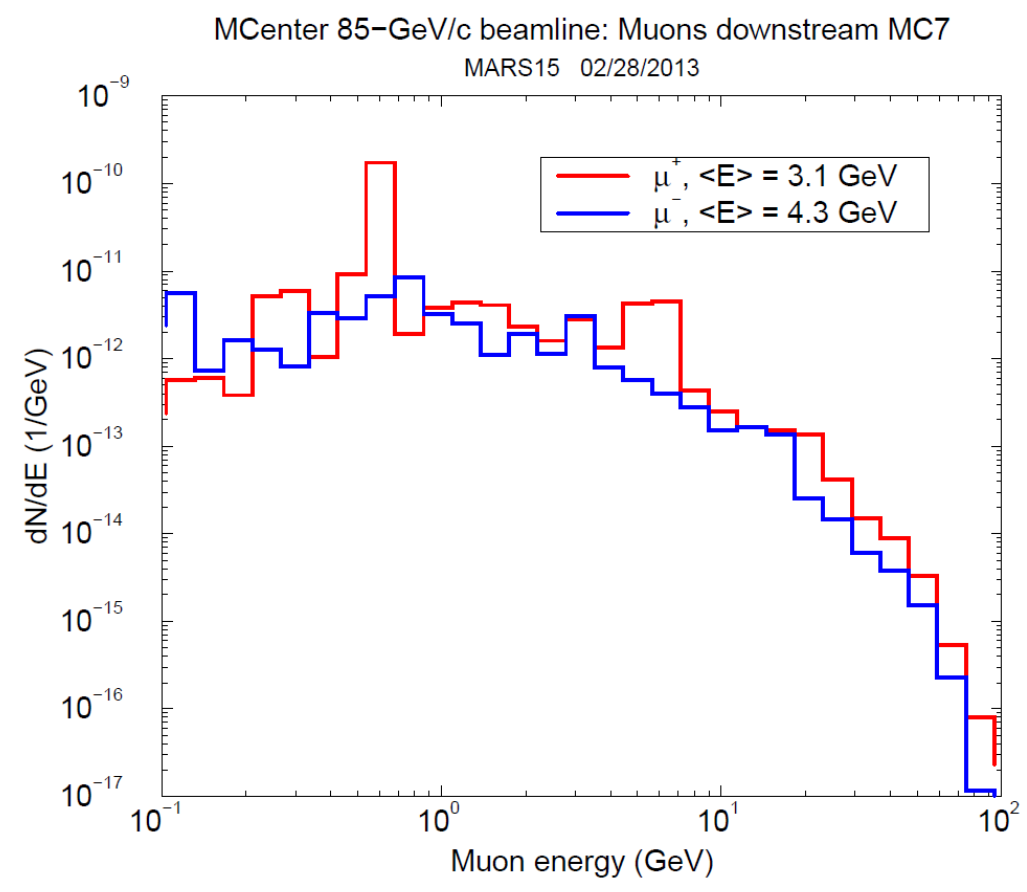

Figure 19. Muon spectra downstream of $\mathrm{MC7}$ for $85-\mathrm{GeV} / \mathrm{c}$ mode. 


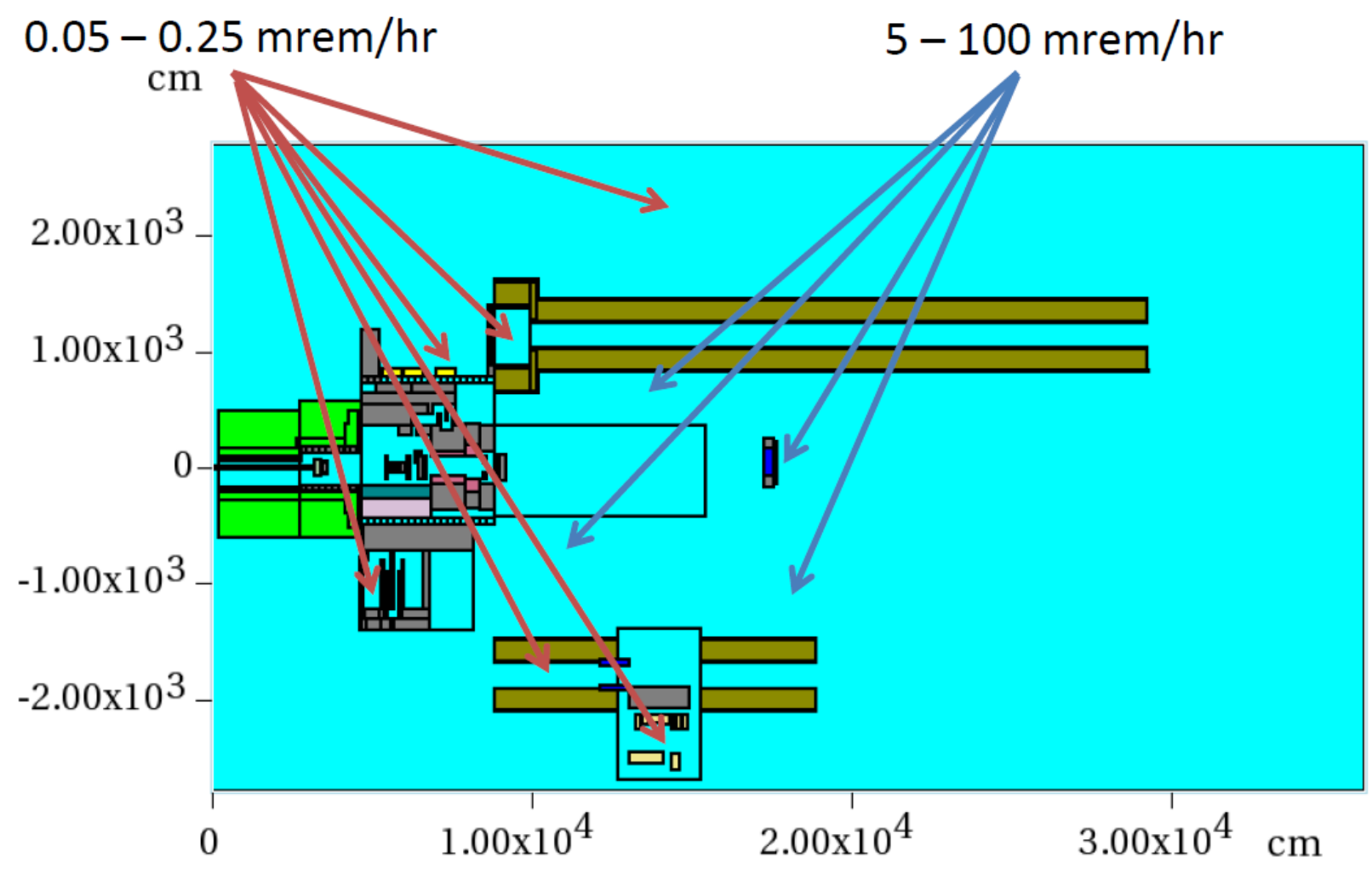

Figure 20. Tolerable dose rates outside MC6 and MC7.
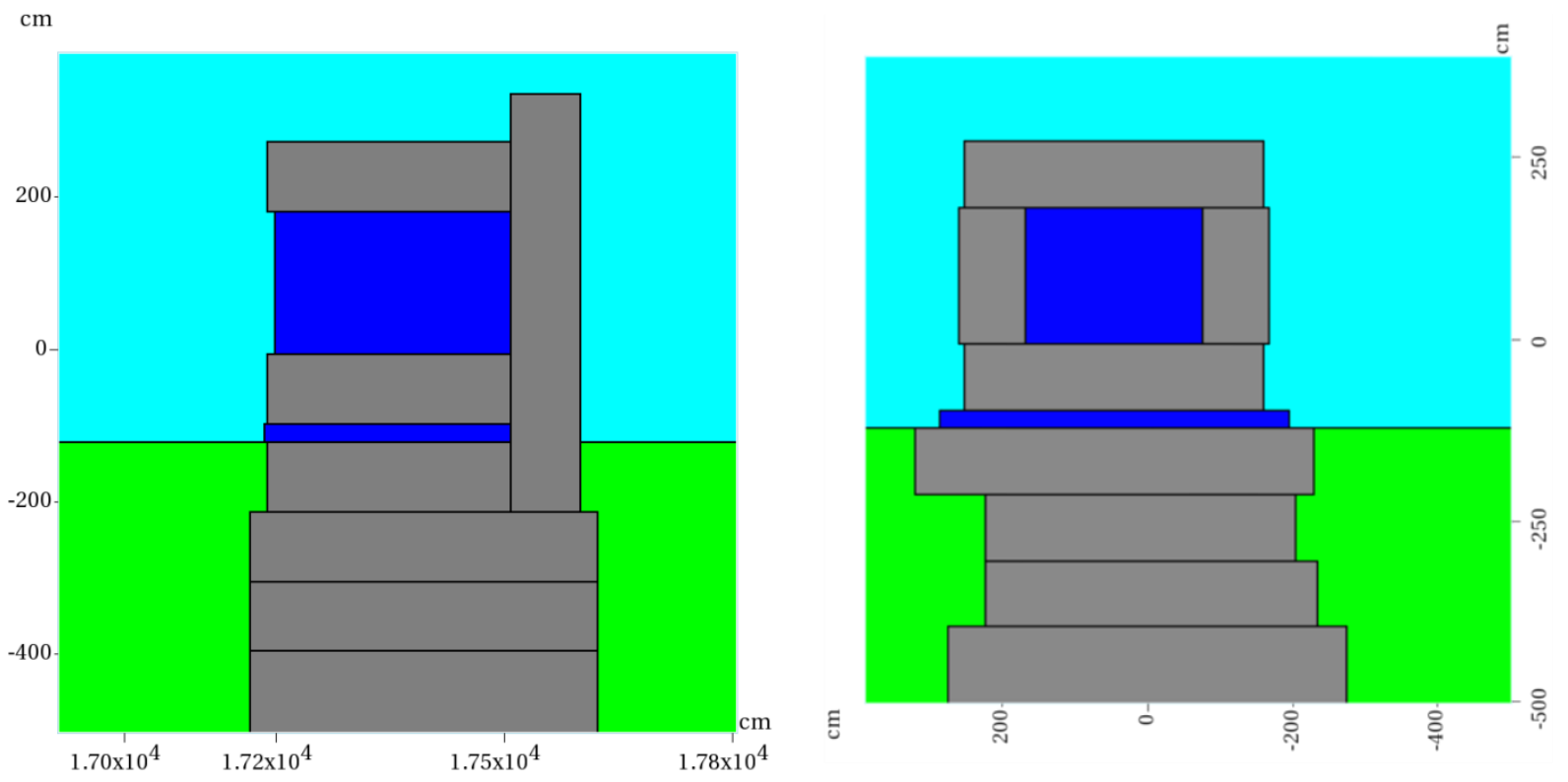

Figure 21. Muon absorber downstream MC7 as implemented in MARS15 model. Color ID: steel core and baseplate (dark blue), concrete shielding (grey), soil (green) and air (light blue). 

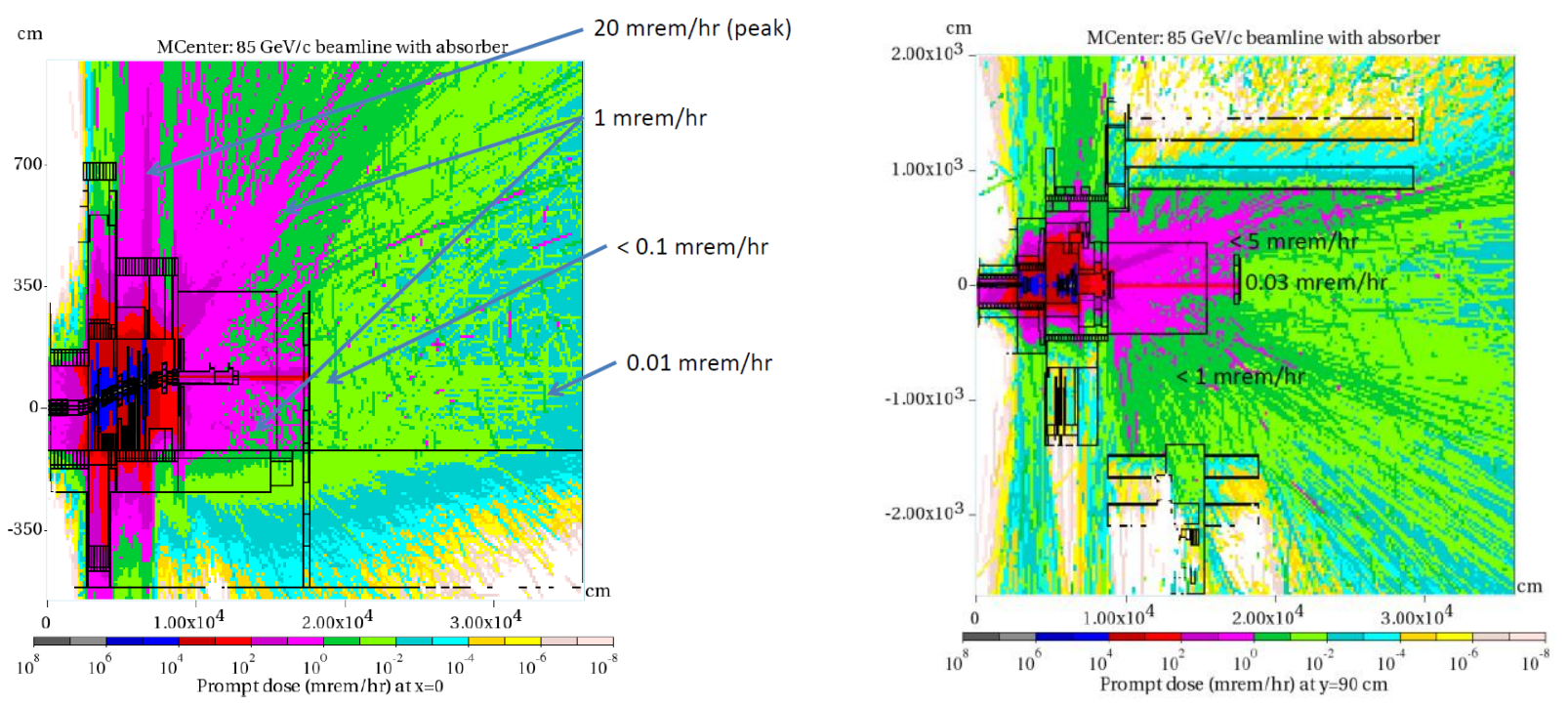

Figure 22. Prompt dose around MCenter for $85-\mathrm{GeV} / \mathrm{c}$ beam: elevation (left) and plan (right) sections.

Fig. 23 shows the plan view of the prompt dose distributions in the MCenter central region for two heights, $0<\mathrm{y}<1 \mathrm{~m}$ and $1<\mathrm{y}<3 \mathrm{~m}$. Star density and hadron flux distributions in MC6 - the hottest region of MCenter - are given in Fig. 24. The calculated star density peak in the first $10-\mathrm{cm}$ of soil under the floor is $210 \mathrm{~cm}^{-3} \mathrm{~s}^{-1}$., about a factor of two higher than for the $16-\mathrm{GeV} / \mathrm{c}$ mode. At the same location, the corresponding peak hadron flux $(E>30 \mathrm{MeV})$ is $7300 \mathrm{~cm}^{-2} \mathrm{~s}^{-1}$. These results confirm again a good performance of MCenter shielding.
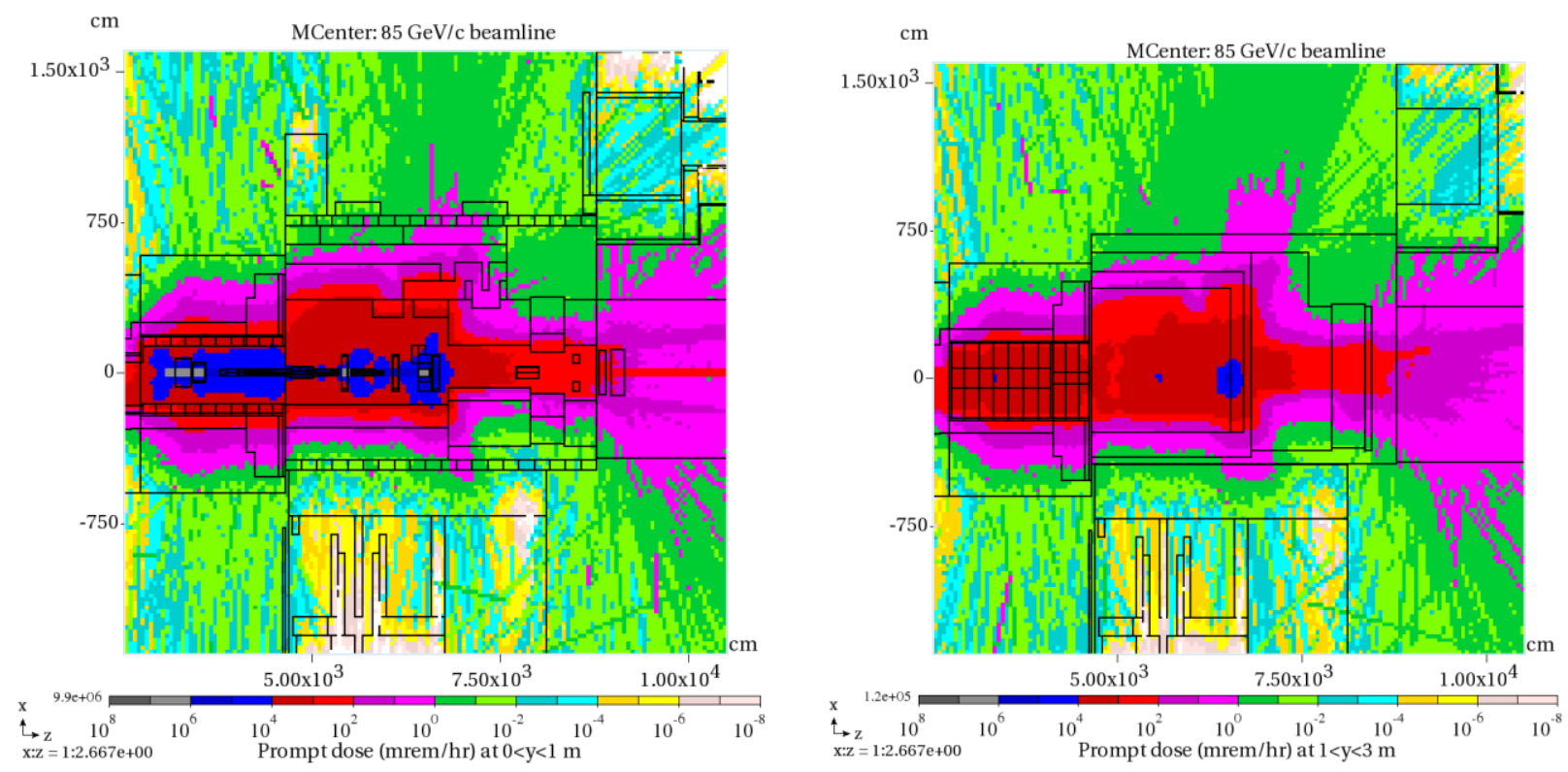

Figure 23. Prompt dose horizontal distributions in the MCenter central region for $85-\mathrm{GeV} / \mathrm{c}$ beam at two heights: $0<\mathrm{y}<1 \mathrm{~m}$ (left) and $1<\mathrm{y}<3 \mathrm{~m}$ (right). 

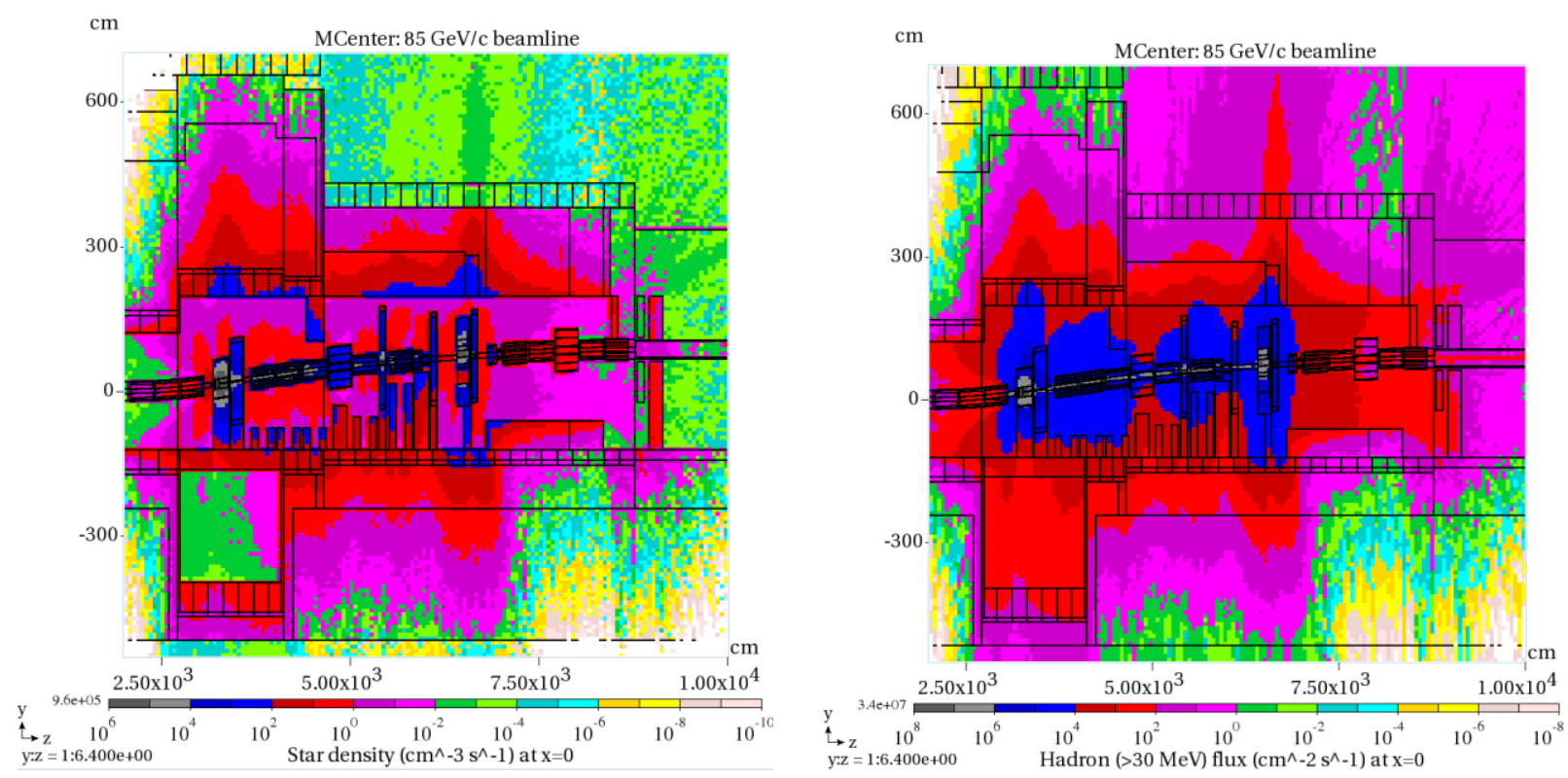

Figure 24. Star density (left) and hadron flux above $30 \mathrm{MeV}$ (right) distribution in MCenter for $85 \mathrm{GeV} / \mathrm{c}$ beam - elevation section.

\section{Summary}

Table 3 lists the results of the MARS15 calculations for the entire model with elements listed in Table 2. Some of the results of earlier runs for the 5 and $16 \mathrm{GeV} / \mathrm{c}$ beamline modes have been rescaled to the ultimate configuration. One sees that the dose and star density in the regions of interest are within the declared limits. Therefore the current configuration of shielding in MCenter is acceptable for its planned operation. Output of the runs is included in separate documents.

Table 3: Prompt dose and star density in the MCenter regions of interest.

\begin{tabular}{|l|l|l|l|l|l|}
\hline Area & Quantity & $5 \mathrm{GeV} / \mathrm{c}$ & $16 \mathrm{GeV} / \mathrm{c}$ & $85 \mathrm{GeV} / \mathrm{c}$ & Acceptable \\
\hline $\begin{array}{l}\text { Top of the } \\
\text { target pile }\end{array}$ & {$[\mathrm{mrem} / \mathrm{hr}]$} & 8 & 15 & 20 & Yes \\
\hline $\begin{array}{l}\text { Floor of the } \\
\text { Meson detector } \\
\text { building }\end{array}$ & {$[\mathrm{mrem} / \mathrm{hr}]$} & 0.1 & 0.1 & $0.05-0.25$ & Yes \\
\hline $\begin{array}{l}\text { New control } \\
\text { room }\end{array}$ & {$[\mathrm{mrem} / \mathrm{hr}]$} & $<0.01$ & $<0.01$ & 0.02 & Yes \\
\hline $\begin{array}{l}\text { Outside areas } \\
\text { within the } \\
\text { radiation fence }\end{array}$ & {$[\mathrm{mrem} / \mathrm{hr}]$} & 0.2 & 0.5 & $<1$ & Yes \\
\hline $\begin{array}{l}\text { Area beyond } \\
\text { the radiation } \\
\text { fence }\end{array}$ & {$[\mathrm{mrem} / \mathrm{hr}]$} & $<1$ & $<1$ & $<1$ & Yes \\
\hline
\end{tabular}




\begin{tabular}{|l|l|l|l|l|l|}
\hline $\begin{array}{l}\text { Below the floor } \\
\text { of the Meson } \\
\text { detector } \\
\text { building }\end{array}$ & [stars/cc/s] & 50 & 118 & 210 & Yes \\
\hline
\end{tabular}

\section{Acknowledgments}

We are thankful to Tom Kobilarcik and Wayne Schmitt for fruitful discussions and invaluable help in the course of this study.

\section{References}

[1] N.V. Mokhov, "The Mars Code System User's Guide", Fermilab-FN-628 (1995);

N.V. Mokhov, S.I. Striganov, "MARS15 Overview", Fermilab-Conf-07/008-AD (2007) in Proc. of Hadronic Shower Simulation Workshop, Fermilab, Sep. 2006, AIP Conf. Proc. 896, pp. 50-60 (2007); http://www-ap.fnal.gov/MARS/

[2] M.A.Kostin. "MARS Calculation for MIPP (FNAL-E907) Shielding Assessment". Fermilab Technical Note, Dec. 2003. 